\title{
Microwave-Assisted Extraction of Essential Oil from Eucalyptus: Study of the Effects of Operating Conditions
}

\author{
A.A. Saoud*1, R.M. Yunus² and R.A. Aziz ${ }^{3}$ \\ ${ }^{1}$ Curtin University of Technology, School of Engineering and Science, CDT 250, 98009 Miri, Sarawak, Malaysia \\ ${ }^{2}$ Faculty of Chemical \& Natural Resources Engineering, University of Teknologi, 81310 Skudai, Johar, Malaysia \\ ${ }^{3}$ Chemical Engineering Pilot Plant, Faculty of Chemical \& Natural Resources Engineering, University Teknologi, 81310 Skudai, \\ Johar, Malaysia
}

Received 27 November 2004; accepted 28 May 2005

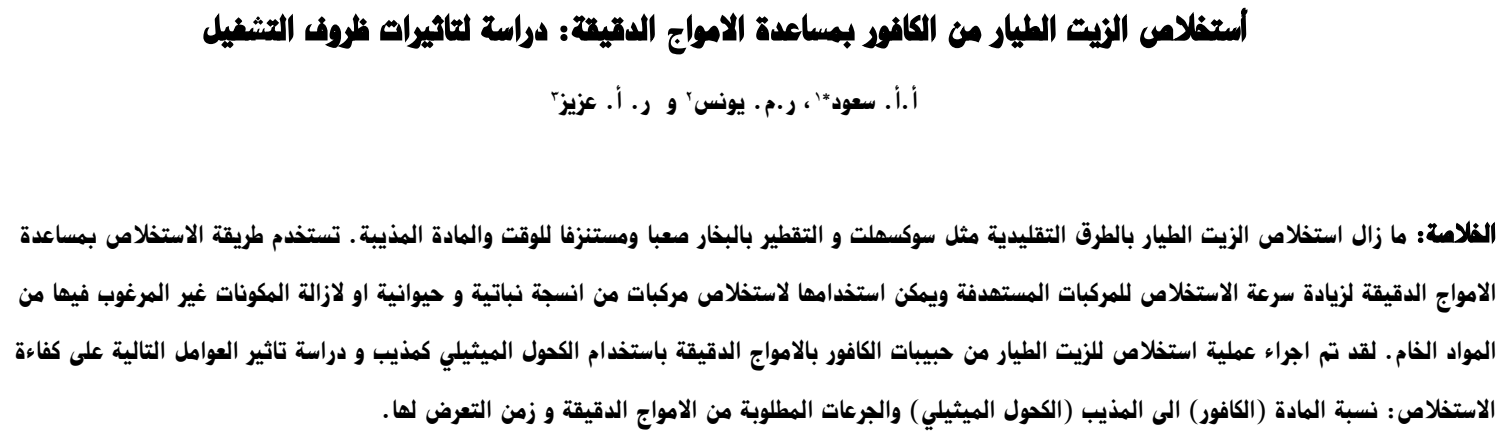

الهنرهات الهنتاهية: الزيت الطيار ، الامواج الدقيقة، الكحول الميثيلي ، الكافور ، الاستخلاص .

\begin{abstract}
Classical extraction of essential oil such as Soxhlet and steam distillation is still a formidable and time-solvent consuming. Microwave assisted process (MAP) is used to accelerate the extraction process of target compounds. It can be used for the extraction of compounds from various plants and animal tissues, or the extraction of undesirable components from raw materials. The investigation of microwave extraction of eucalyptus (globules) essential oil using ethanol as solvent was carried out. The influence of material (eucalyptus)/solvent (ethanol) ratio, required doses of microwave, and time of microwave exposure on extraction efficiency, was studied.
\end{abstract}

Keywords: Essential oil, Microwave, Ethanol, Eucalyptus, Extraction

\section{Introduction}

Essential oils can be broadly defined as volatile oils that differ fundamentally from the fixed fatty oils such as linseed, coconut and olive in being more mobile and volatile. Many essential oils, apart from being used for first aid or for treatment of common complaints, are also ideal as bath oils, perfumes or room fresheners. Even when they are used purely for aesthetic purposes, they still play a positive preventive and therapeutic role (Lawless, 1997). Conventional extraction of essential oils includes: tumbling and shaking, oil infusion, cold expression, steam distillation and Soxhlet extraction can take from hours to days, and requires significant amounts of

*Corresponding author’s e-mail: amer@curtin.edu.my solvent. Following the results of the various experiments carried out, it becomes obvious that extraction using microwave technology is a good alternative to conventional extraction techniques. The extraction by microwave as a new extraction technique has its own specific parameters that need to be characterized for every plant that contains essential oil. When a material is exposed to microwaves, the polar molecules within the matrix become excited. Then they orient themselves in the direction opposite to the field. The frequency of the change of polarity of the electric field determines the frequency at which the molecules will rotate within the field. As a result of this rotation, temperatures in the vicinity of the rotating molecule increase. The applied field prevents the molecules from reaching an equilibrium position and, thus, the polar molecules store potential energy while they 
are within the field. When the field is removed, the molecules relax to an equilibrium position and release excess kinetic energy in the form of heat. Microwave applicability for the extraction of various types of compounds from plant material, food and soil was investigated by Ganzler et al. (1986). The production of volatile material from plant exposed to microwave energy in an air stream has been discussed by Craveiro et al. (1989). Chen and Spiro (1994) studied the microwave heating characteristics of extraction of rosemary and peppermint leaves suspended in hexane, ethanol and mixture of hexane and ethanol. Pare (1995) patented a general extraction method for biological matter using microwave energy and a microwave transparent solvent. Weseler et al. (2002) has studied the antibacterial activity of Australian tea-tree oil against several strains of Malassezia pachydermatis. Different solvents such as ethanol, trichloromethane, cyclohexane, nhexane, were used to study the effect of solvency on the extraction of artemisinin from Artemisia annua using microwave-assisted process by Jin-yu Hao et al. (2002). Marie et al. (2004) used a new microwave technique -solvent free microwave extraction- (SFME) to extract essential oil from basil (Ocimum basilicum L.), garden mint (Mentha crispa L.), and thyme (Thymus vulgaris L.). The findings showed the aromatic profile of microwave exposure are similar to those obtained by hydrodistillation for $4.5 \mathrm{~h}$.

This work is concerned with the optimization of microwave parameters: eucalyptus/ethanol ratio, required doses of microwave, heating then cooling that lead to sequence of sudden expansion to help breaking the gland faster and, thus, released more solutes into the extracting solvent, and time of exposure. Different ratios of eucalyptus leaves/ethanol have been examined in order to obtain the optimal material/solvent ratio gives highest yield of extracted essential oil. The required number of microwave doses that provides an accomplishing extraction process has been ascertained. The optimal time of microwave was determined.

\section{Experimental Procedure}

\subsection{Materials and Chemicals}

Standard samples of the major eucalyptus constituents (cineole, $\alpha$-pinene, camphene, cymene, limonene and $\gamma$ terpinene) of high purity (purchased from Sigma-Aldrich) were used in this study for GC calibration. The calibration was done by preparing known concentrations of each component in ethanol solution and the samples were introduced to the GC for analysis. The peaks obtained provide the retention time and the corresponding area, representing the component concentration. Leaves of eucalyptus plant were supplied by Nasuha Enterprise Plantation (Malaysia). Ethanol of $96 \mathrm{v} / \mathrm{v} \%$ was supplied by FlukaSwitzerland.

\subsection{Equipment}

In this study, gas chromatography (GC, Perkin Elmer-
Auto system XL Gas Chromatograph) was utilized for the analysis of the extracts. Computerized microwave solvent extraction system (Milestone-Ethos Sel microwave lab station) was used for microwave extraction.

\subsection{Procedure}

In order to measure the optimal material/solvent ratio, required number of microwave doses, and exposure time, the following procedure was pursued: samples of eucalyptus leaves were placed in sealed containers of $270 \mathrm{ml}$ of each. Equal volumes $(100 \mathrm{ml})$ of solvent (ethanol) was used throughout the tests. A magnetic stirrer agitated the solution. In between each dose of exposure, the solutions were allowed to cool back to room temperature $\left(28^{\circ} \mathrm{C}\right)$. Sampling of $2 \mathrm{ml}$ was carried out at the end of each dose of exposure, thus, the solute concentrations were corrected taking into account the change in solution volume. The extraction was done in sealed vessels, where no evaporation was observed. All solute concentrations are reported in $\mathrm{mg} / \mathrm{L}$. Power of $1000 \mathrm{~W}$ was used in the experiments. Equation (1) was used to correct the concentration due to sampling:

$$
\mathrm{C}=\mathrm{C}_{\mathrm{n}}[\mathrm{V}-2(\mathrm{~N}-1] / \mathrm{V}
$$

where

$\mathrm{C}=$ corrected concentration $(\mathrm{mg} / \mathrm{L})$

$\mathrm{C}_{\mathrm{n}}=$ concentration obtained directly from chromatogram $(\mathrm{mg} / \mathrm{L})$

$\mathrm{N}=$ number of sampling

$\mathrm{V}=$ initial volume of solvent $(100 \mathrm{ml})$

\section{Results and Discussions}

\subsection{Influence of Eucalyptus/Ethanol Ratio on Microwave Extraction}

Tables 1-5 show the constituent concentrations for different ratios of eucalyptus/ethanol at same conditions of time and power. The total amounts of cineole, $\alpha$-pinene, limonene, cymene, $\gamma$-terpinene, and camphene that can be extracted by microwave extraction, showed an increasing trend of extracted constituents with the increase in exposure doses. Obviously, it can be deduced that ethanol can extract eucalyptus essential oil for the ratio of 2, 4 and $6 \mathrm{~g}$ of eucalyptus/100 mL ethanol, but for the ratios of 8 and $10 \mathrm{~g}$, ethanol could not extract more essential oil due to over saturation. Figures 1-6 show the concentrations of each constituent at different ratios and successive ten doses per one $\mathrm{g}$ of leaves in order to make comparison among different ratios used. Cineole could be detected from first dose at all ratios while $\alpha$-pinene could not be detected for the ratio of $2 \mathrm{~g}$, but it appeared for the rest of the ratios. For the ratios of 2 and $4 \mathrm{~g}$, limonene was not observed; but at 6 and $8 \mathrm{~g}$ it needs minimum of 8 doses to appear; while at $10 \mathrm{~g}$ it could be taken out from the second dose. Cymene was extracted at all ratios, but it needs 10 doses for the first ratio (2 g); while for the ratio of $4 \mathrm{~g}$, 7 doses were sufficient. For ratios of 6 and $8 \mathrm{~g}$, it needed 
five doses; whilst at the ratio of $10 \mathrm{~g}$, it was appreciable from the first dose. Camphene and $\gamma$-terpinene showed similar readiness of extraction for all ratios but at different doses. The results showed that at the ratio of $6 \mathrm{~g}$ leaves/100 mL ethanol, maximum extraction could be obtained. At this ratio, the yield of essential oil was 3.576 $\mathrm{mg} / \mathrm{g}$ eucalyptus of fresh leaves. The percentage of major constituent (cineole) was 68; while for $\alpha$-pinene and limonene it was $16 \%$ and $8 \%$ respectively, the rest of constituents (cymene, $\gamma$-terpinene, and camphene) represent $8 \%$.

\subsection{Influence of Exposure Doses on Microwave Extraction}

Microwave extraction technique works by exposing the material to a sudden heat caused by the microwave field, to integrate this process, a successive exposing and cooling are required. After each microwave exposure, the

Table 1. Constituent concentrations $(\mathrm{mg} / \mathrm{mL})$ of the ratio $2 \mathrm{~g}$ eucalyptus/100 $\mathrm{mL}$ ethanol, 60 seconds exposure and $1000 \mathrm{~W}$

No. of doses

$\begin{array}{lcccccccccc}\text { Constituents } & \mathbf{1} & \mathbf{2} & \mathbf{3} & \mathbf{4} & \mathbf{5} & \mathbf{6} & \mathbf{7} & \mathbf{8} & \mathbf{9} & \mathbf{1 0} \\ \text { cineole } & 3.27 & 3.36 & 3.52 & 3.81 & 3.90 & 4.17 & 4.21 & 4.26 & 4.87 & 4.89 \\ \alpha \text {-pinene } & - & - & - & - & - & - & - & - & - & - \\ \text { limonene } & - & - & - & - & - & - & - & - & - & - \\ \text { cymene } & - & - & - & - & - & - & - & - & - & 0.12 \\ \gamma \text {-terpinene } & - & - & - & - & - & - & - & - & 0.32 & 0.33 \\ \text { camphene } & - & - & - & - & - & - & - & - & 0.12 & 0.13\end{array}$

Table 2. Constituent concentration $(\mathrm{mg} / 100 \mathrm{~mL})$ of the ratio $4 \mathrm{~g}$ eucalyptus $/ 100 \mathrm{~mL}$ ethanol, 60 seconds exposure and $1000 \mathrm{~W}$

$\begin{array}{lcccccccccc}\text { Constituents } & \mathbf{1} & \mathbf{2} & \mathbf{3} & \mathbf{4} & \mathbf{5} & \mathbf{6} & \mathbf{7} & \mathbf{8} & \mathbf{9} & \mathbf{1 0} \\ \text { cineole } & 5.49 & 5.66 & 5.72 & 6.09 & 6.13 & 8.13 & 8.22 & 8.56 & 9.42 & 9.44 \\ \alpha \text {-pinene } & - & - & - & - & - & - & - & 1.81 & 2.30 & 2.32 \\ \text { limonene } & - & - & - & - & - & - & - & - & - & - \\ \text { cymene } & - & - & - & - & - & - & 0.13 & 0.18 & 0.25 & 0.25 \\ \gamma \text {-terpinene } & - & - & - & - & - & 0.33 & 0.44 & 0.53 & 0.64 & 0.66 \\ \text { camphene } & - & - & - & - & - & 0.13 & 0.17 & 0.23 & 0.25 & 0.25\end{array}$

Table 3. Constituent concentration $(\mathrm{mg} / 100 \mathrm{~mL})$ of the ratio $6 \mathrm{~g}$ eucalyptus/100 $\mathrm{mL}$ ethanol, 60 seconds exposure and $1000 \mathrm{~W}$

\begin{tabular}{lcccccccccc} 
& & \multicolumn{1}{c}{ No. of doses } \\
Constituents & $\mathbf{1}$ & $\mathbf{2}$ & $\mathbf{3}$ & $\mathbf{4}$ & $\mathbf{5}$ & $\mathbf{6}$ & $\mathbf{7}$ & $\mathbf{8}$ & $\mathbf{9}$ & $\mathbf{1 0}$ \\
cineole & 8.27 & 8.96 & 9.52 & 10.81 & 11.90 & 12.70 & 13.10 & 14.25 & 14.57 & 14.58 \\
$\alpha$-pinene & - & - & - & - & 1.83 & 2.41 & 2.84 & 3.10 & 3.39 & 3.42 \\
limonene & - & - & - & - & - & - & - & 1.08 & 1.68 & 1.70 \\
cymene & - & - & - & - & 0.13 & 0.20 & 0.26 & 0.31 & 0.37 & 0.38 \\
$\gamma$-terpinene & - & - & 0.32 & 0.47 & 0.59 & 0.66 & 0.75 & 0.88 & 0.95 & 0.98 \\
camphene & - & - & - & - & 0.13 & 0.24 & 0.30 & 0.35 & 0.39 & 0.39
\end{tabular}

Table 4. Constiturent concentration $(\mathrm{mg} / 100 \mathrm{~mL})$ of the ratio $8 \mathrm{~g}$ eucalyptus/100 $\mathrm{mL}$ ethanol, 60 seconds exposure and $1000 \mathrm{~W}$

No. of doses

$\begin{array}{lcccccccccc}\text { Constituents } & \mathbf{1} & \mathbf{2} & \mathbf{3} & \mathbf{4} & \mathbf{5} & \mathbf{6} & \mathbf{7} & \mathbf{8} & \mathbf{9} & \mathbf{1 0} \\ \text { cineole } & 10.31 & 11.36 & 11.52 & 12.81 & 13.90 & 14.70 & 15.10 & 15.25 & 16.82 & 16.89 \\ \alpha \text {-pinene } & - & - & 1.87 & 2.15 & 2.63 & 2.70 & 2.81 & 2.96 & 3.64 & 3.65 \\ \text { limonene } & - & - & - & - & - & - & - & 1.12 & 1.80 & 1.83 \\ \text { cymene } & - & - & - & - & 0.13 & 0.19 & 0.26 & 0.32 & 0.41 & 0.41 \\ \gamma \text {-terpinene } & 0.33 & 0.38 & 0.43 & 0.50 & 0.61 & 0.78 & 0.86 & 0.96 & 1.10 & 1.12 \\ \text { camphene } & - & - & 0.14 & 0.18 & 0.22 & 0.28 & 0.31 & 0.35 & 0.38 & 0.40\end{array}$


Table 5. Constituent concentration $(\mathrm{mg} / 100 \mathrm{~mL})$ of the ratio $10 \mathrm{~g}$ eucalyptus/100 $\mathrm{mL}$ ethanol, 60 seconds exposure and $1000 \mathrm{~W}$

$\begin{array}{lcccccccccc}\text { Constituents } & \mathbf{1} & \mathbf{2} & \mathbf{3} & \mathbf{4} & \mathbf{5} & \mathbf{6} & \mathbf{7} & \mathbf{8} & \mathbf{9} & \mathbf{1 0} \\ \text { cineole } & 13.30 & 14.32 & 15.57 & 15.90 & 16.58 & 17.62 & 18.83 & 19.60 & 20.74 & 20.76 \\ \alpha \text {-pinene } & 2.56 & 2.83 & 3.11 & 3.32 & 3.65 & 3.76 & 3.91 & 4.21 & 4.84 & 4.85 \\ \text { limonene } & - & 1.11 & 1.30 & 1.41 & 1.46 & 1.49 & 1.55 & 1.72 & 1.86 & 1.88 \\ \text { cymene } & 0.13 & 0.20 & 0.27 & 0.30 & 0.31 & 0.33 & 0.36 & 0.44 & 0.53 & 0.55 \\ \gamma \text {-terpinene } & 0.38 & 0.39 & 0.43 & 0.46 & 0.62 & 0.78 & 0.85 & 0.93 & 1.15 & 1.16 \\ \text { camphene } & - & 0.13 & 0.14 & 0.19 & 0.24 & 0.28 & 0.32 & 0.37 & 0.41 & 0.41\end{array}$

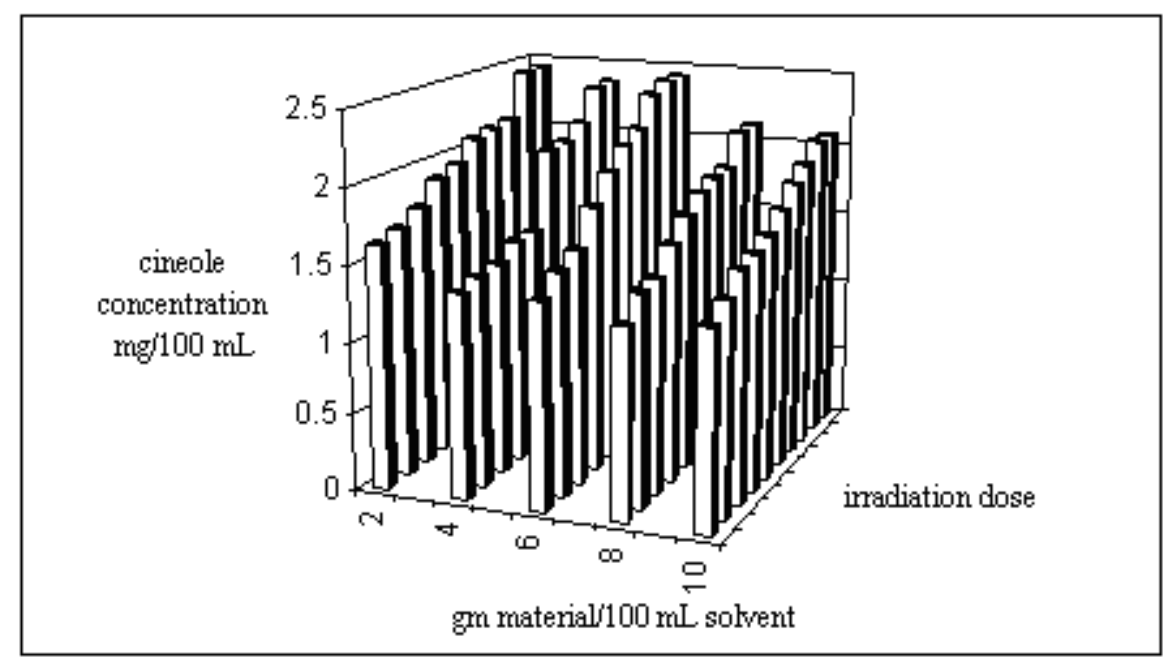

Figure 1. Cineole cumulative concentration-microwave dose plot at $1000 \mathrm{~W}$ and 60 seconds at different eucalylptus/ethanol ratios

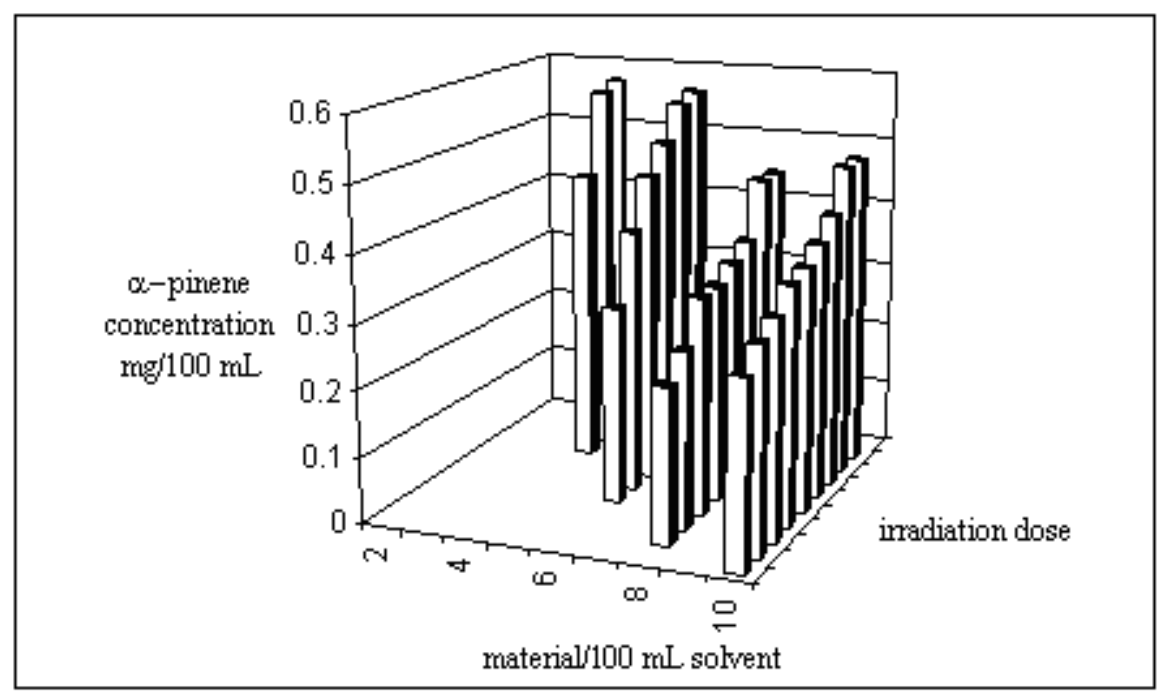

Figure 2. $\alpha$ - pinene cumulative concentration-microwave dose plot at $1000 \mathrm{~W}$ and 60 seconds at different eucalyptus/ethanol ratios 


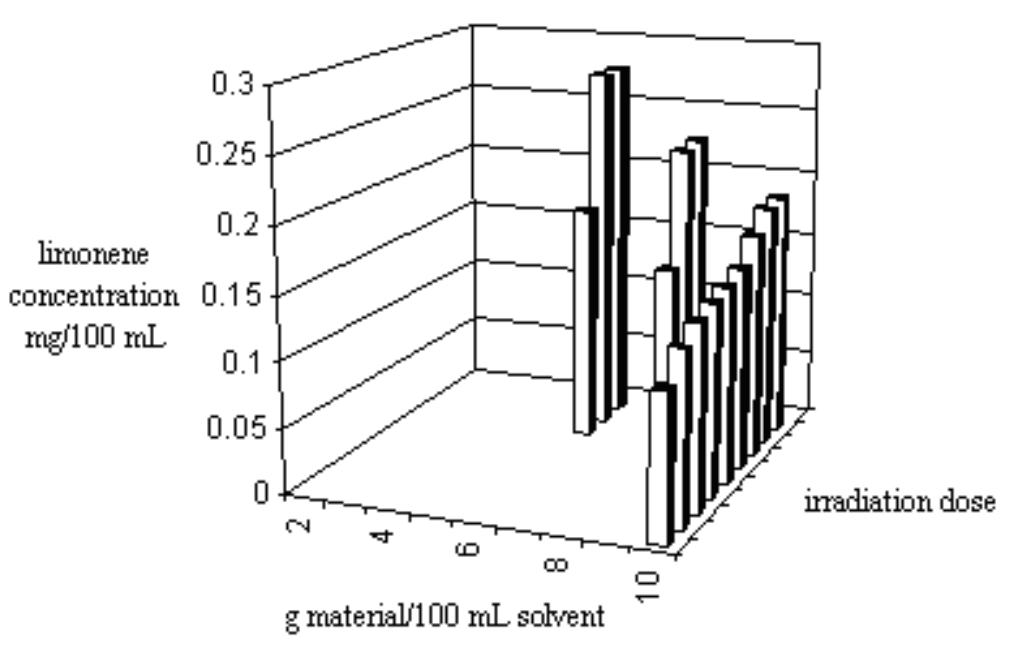

Figure 3. Limonene cumulative concentration-microwave dose plot at $1000 \mathrm{~W}$ and 60 seconds at different eucalyptus/ethanol ratios

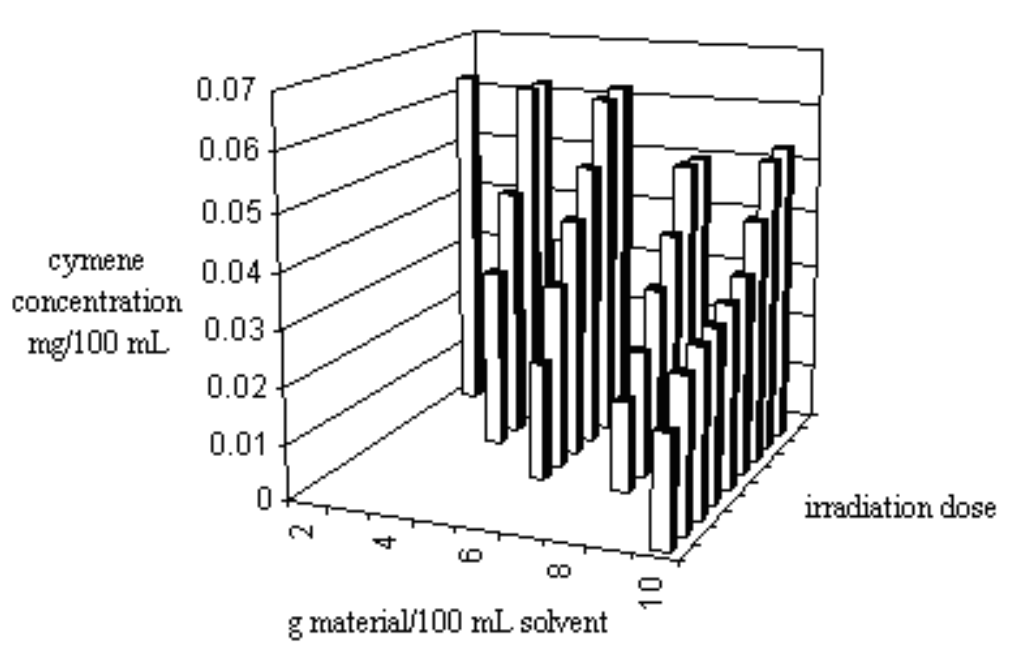

Figure 4. Cymene cumulative concentration-microwave dose plot at $1000 \mathrm{~W}$ and 60 seconds at different eucalyptus/ethanol ratios

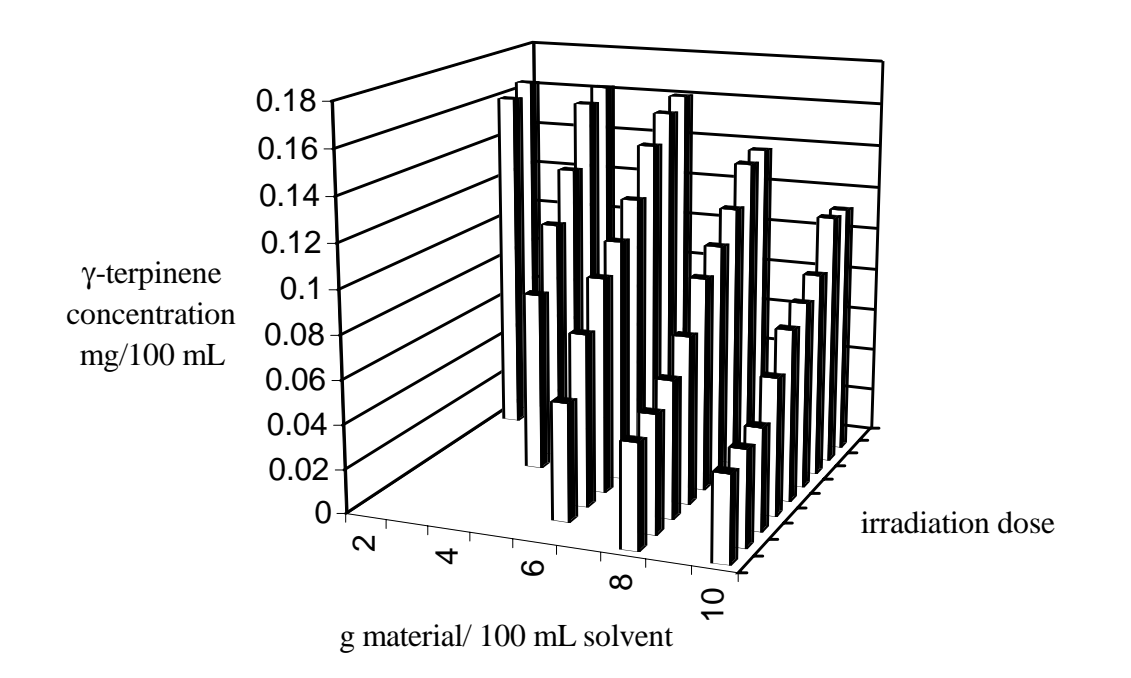

Figure 5. $\gamma$-terpinene cumulative concentration-microwave dose plkot at $1000 \mathrm{~W}$ and 60 seconds at different eucalyptus/ethanol ratios 


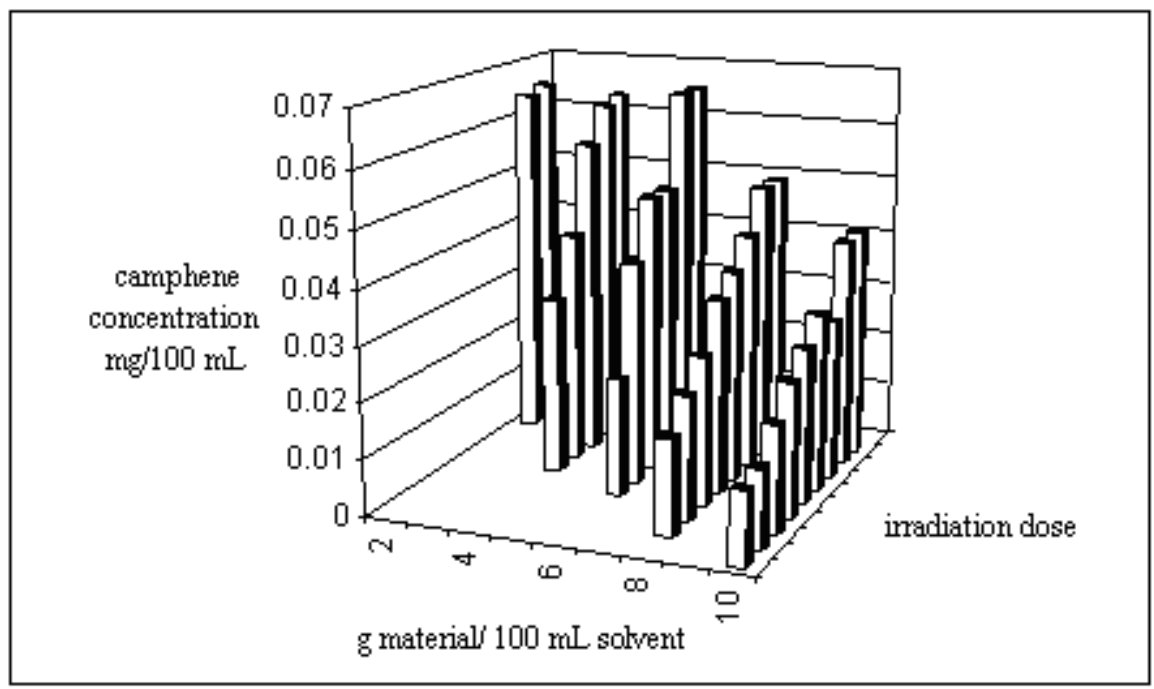

Figure 6. Camphene cumulative concentration-microwave dose plot at $1000 \mathrm{~W}$ and 60 seconds at different eucalyptus/ethanol ratios

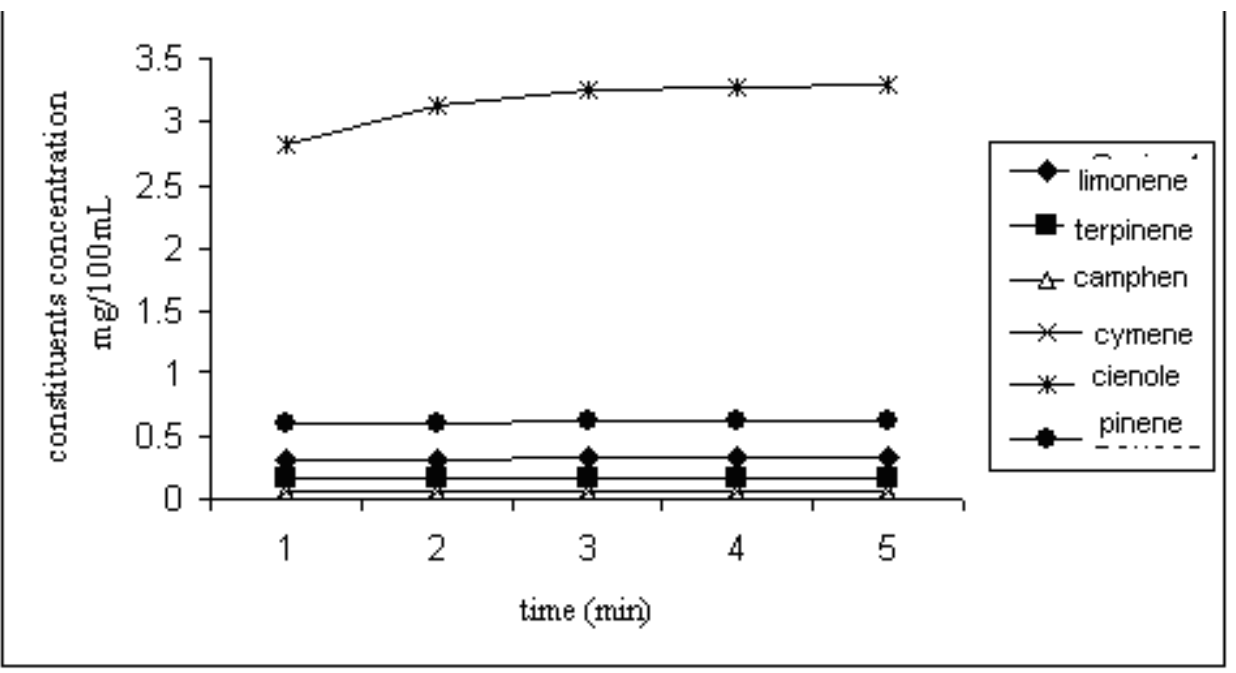

Figure 7. Eucalyptus essential oil constituent concentrations per g of eucalyptus leaves at different microwave exposure times

solution was allowed to cool back to room temperature $\left(28{ }^{\circ} \mathrm{C}\right)$. The natural cooling process helped releasing more solutes from the solid matter and allowed the solute contained gland to return to its original size. The number of microwave doses and corresponding constituents' concentrations are listed in Tables 1-5. Ten doses of exposure are required due to the adjacent values of concentrations obtained at 9 and 10 doses. Hence, the required number for successive exposing and cooling that provides an accomplishing extraction process to achieve the equilibrium of extraction is ten.

\subsection{Influence of Microwave Exposure Time on Eucalyptus Essential Oil Extraction}

Microwave exposure was tested for times of 1 to 5 minutes to inspect the influence of exposure time on the essential oil extraction at $1000 \mathrm{~W}$, material /solvent ratio of $6 \mathrm{~g} / 100 \mathrm{~mL}$ ethanol and 10 successive doses. The tem- perature increases $(\Delta \mathrm{T})$ measured were $25,40,56,68$ and $80^{\circ} \mathrm{C}$. Figure 7 shows the concentration of the constituents measured with an exposure time of 3 minutes, which brings about equilibrium and gives highest yield. Cineole concentration increased with time and reached the equilibrium at 3 minutes of exposure; while the other constituent concentrations showed plateau condition, which indicates that equilibrium condition has been reached much earlier (during the first minute of exposure). Optimization of time of exposure yielded $4.50 \mathrm{mg} / \mathrm{g}$ of eucalyptus from the fresh leaves. The content of cineole, $\alpha$-pinene and limonene were $72 \%, 13.6 \%$ and $7.1 \%$ respectively.

\section{Conclusions}

Material-solvent ratio has an important influence on microwave extraction of eucalyptus leaves in ethanol. The results showed that the highest concentration was 
obtained at the ratio of $6 \mathrm{~g}$ leaves $/ 100 \mathrm{~mL}$ ethanol. Ten exposure doses were required to achieve the equilibrium extraction. Microwave exposure time of 3 minutes was enough for microwave extraction process. The yield of eucalyptus essential oil was $4.5 \mathrm{mg} / \mathrm{g}$ fresh leaves under the conditions: $6 \mathrm{~g} / 100 \mathrm{~mL}$ ethanol, 10 doses of exposure, microwave power delivered at $1000 \mathrm{~W}$, exposure time of 3 minutes.

\section{References}

Chen, S. and Spiro, M., 1994, "Study of Microwave Extraction of Essential Oil Constituents from Plant Materials," J. Microwave Power Electromagnetic Energy, Vol. 29, pp. 231-241.

Craveiro, A.A., Matos, F.J.A. and Alencar, J.W., 1989, "Microwave Extraction of an Essential Oil," J. Flavor and Fragrance, Vol. 4, pp. 43-44.

Ganzler, K., Salgo, A. and Volko, K., 1986, "Determination of Lead Contented on Particulate Matter Filters By Microwave Extraction and Analysis by Atomic Absorption Spectrometry," $J$.
Chromatography, Vol. 371, pp. 299-306.

Hao, J., Han, W., Huang, S., Xue, B. and Deng, X., 2002, "Microwave-Assisted Extraction of Artemisinin from Artemisia Annua L," J. Separation and Purification Technology, Vol. 28, pp. 191-196.

Lawless, J., 1997, "The Complete Illustrated Guide to Aromatherapy," Element Books Limited, pp. 18-25.

Marie, E. L., Farid, C. and Jacqueline, S., 2004, "Solvent Free Microwave Extraction of Essential Oil from Aromatic Herbs: Comparison with Conventional Hydro-Distillation," J. of Chromatography, Vol. 1043, pp. 323-327.

Pare, J.R.J., 1995, "Microwave-Assisted Extraction from Materials Containing Organic Matter," US Patent, Vol. 5, pp. 458, 897.

Weseler, A., Geiss, H.K., Saller, R. and Reichling, J., 2002, "Antifungal Effect of Australian Tea Tree Oil on Malassezia Pachydermatis Isolated from Canines Suffering from Cutaneous Skin Disease", $J$. Schweizer Archiv Fur Tierheilkunde, Vol. 144, pp. 215-221. 